\title{
Seizure disorders in pregnancy: an insight beyond eclampsia and epilepsy
}

\section{Arti Sharma $^{1 *}$, Vineeta Gupta ${ }^{1}$, Prashant Sarda ${ }^{2}$, Parul Singh ${ }^{1}$, Nikita Gupta ${ }^{1}$, Swati Kohli $^{1}$}

\author{
${ }^{1}$ Department of Obstetrics and Gynaecology, ${ }^{2}$ Department of Radiodiagnosis, Shri. Guru Ram Rai Institute of Medical \\ and Health Sciences, Dehradun, Uttarakhand, India
}

Received: 12 September 2021

Accepted: 06 October 2021

\section{*Correspondence:}

Dr. Arti Sharma,

E-mail: artishubh@yahoo.com

Copyright: ( $)$ the author(s), publisher and licensee Medip Academy. This is an open-access article distributed under the terms of the Creative Commons Attribution Non-Commercial License, which permits unrestricted non-commercial use, distribution, and reproduction in any medium, provided the original work is properly cited.

\begin{abstract}
Background: Seizures in pregnancy contribute to poor maternal and perinatal outcome. Though eclampsia and epilepsy are common causes of seizures in pregnancy but there are several other conditions apart from eclampsia and epilepsy which give rise to convulsions. Objective of this study was to evaluate fetomaternal outcome in patients with seizure disorders as well as to analyze the other causes of seizures in pregnancy apart from eclampsia and epilepsy.

Methods: This prospective study was conducted in Shri. Guru Ram Rai institute of medical and health sciences, Dehradun, India over a period of 39 months from January 2017to March 2020, in all pregnant women with seizure disorders delivered in this hospital. In all cases demographic characteristics, causes of seizure with special attention on noneclamptic, non-epileptic conditions, maternal complications, mode of delivery and fetal outcome were noted.

Results: Total 97 cases with seizure disorders were included in the study. Mostly seizures were due to eclampsia and epilepsy in $91.75 \%$ cases. Among other causes neurocysticercosis, cerebral malformation, posterior reversible encephalopathy syndrome, brain tumor, and cerebral infarcts contributed to seizures in pregnancy in $8.25 \%$ cases. Maternal complications were premature rupture of membranes, gestational diabetes mellitus, hypothyroidism, anaemia, jaundice and abruption observed in $37.11 \%$ cases. Live birth rate was $76.28 \%$, prematurity was present in $27.83 \%$ cases and fetal growth restriction was seen in $7.21 \%$ neonates. There were $5(5.15 \%)$ neonatal deaths.

Conclusions: Seizure disorders in pregnancy are associated with significant increase in maternal and fetal risk. Maternal complications, cesarean section rate and neonatal complications are increased. Several other conditions apart from eclampsia, need to be considered in patients without epilepsy presenting with convulsions in pregnancy.
\end{abstract}

Keywords: Seizure disorders, Pregnancy, Eclampsia, Epilepsy, Neurocysticercosis

\section{INTRODUCTION}

Seizure disorders in pregnancy contribute to both maternal and perinatal complications. Incidence of seizure disorder in pregnancy is estimated to be $0.3 \%$ to $0.5 \%$ of all births. ${ }^{1}$ Generally seizures occurring in pregnancy are thought to be due to eclampsia. Eclampsia is occurrence of generalized tonic clonic convulsions or coma, in a woman with preeclampsia which cannot be attributed to other causes. It is seen between 20 weeks of gestation and 48 hours postpartum. Atypical cases are those that develop at less than 20 weeks of gestation and after 48 hours postpartum and that have some of the sign and symptoms of preeclampsia-eclampsia without the usual hypertension or proteinuria. ${ }^{2}$ Epilepsy is also a common neurological disorder encountered in pregnancy. There are over 2.5 million women with epilepsy in India, with upto $25 \%$ of them being in the reproductive age group. ${ }^{3}$ There are many causes for seizures in pregnancy other than eclampsia and epilepsy like cerebral infarction, cerebral hemorrhage, neurocysticercosis (NCC), hypertensive encephalopathy, cerebral malaria, 
intracranial neoplasms, meningitis, encephalitis, malformations, metabolic disorders like hypoglycemia, thrombotic thrombocytopenic purpura etc. ${ }^{4}$

\section{Aim and objectives}

The objectives of this study were to analyze the demographic profile, etiological factors, complications and to evaluate fetomaternal outcome in women with seizures in pregnancy. We also analyzed the causes of seizures in pregnancy apart from eclampsia and epilepsy.

\section{METHODS}

This prospective study was conducted on pregnant patients with seizure disorder from January 2017 to March 2020, over a period of 39 months at the department of obstetrics and gynaecology of Shri Guru Ram Rai institute of medical and health sciences, Dehradun, Uttarakhand, India. Total 97 women with seizures in pregnancy, delivered in this hospital were included in the study. These women were managed with a team of obstetrician, neonatologist, neurologist and radiologist. If any patient demonstrated worsening of clinical condition, or presence of atypical symptoms then consultation with neurologist was done and other relevant investigation like magnetic resonance imaging (MRI), electroencephalography (EEG) was done according to the requirement.

Maternal variables analysed were age, parity, causes of seizures, anticonvulsant drugs used, maternal complications, and mode of delivery. Fetal variables observed were live birth, still birth, birth asphyxia, prematurity, growth restriction and neonatal death. All variables were presented as frequencies and percentages.

\section{RESULTS}

In this period there were 9042 deliveries in our hospital. We found 97 women had seizures complicating pregnancy and puerperium, with incidence of $1.07 \%$. Maximum number of cases $44(45.36 \%)$ were in the age group between 21-25 years. Most of the cases 65 $(67.01 \%)$ were primi gravida (Table 1$)$.

Table 1: Demographic characteristics of patients in study population $(n=97)$.

\begin{tabular}{|lll|}
\hline Characteristics & $\mathbf{N}$ & $\%$ \\
\hline Age (years) & & \\
\hline$<21$ & 13 & 13.40 \\
\hline $21-25$ & 44 & 45.36 \\
\hline $26-30$ & 31 & 31.95 \\
\hline $31-35$ & 8 & 8.24 \\
\hline$>35$ & 1 & 1.03 \\
\hline Parity & & \\
\hline Primigravida & 65 & 67.01 \\
\hline Multigravida & 32 & 32.98 \\
\hline
\end{tabular}

Most common cause of seizures in pregnancy was eclampsia $(68.04 \%)$ followed by epilepsy $(23.71 \%)$. Eight women $(8.24 \%)$ had other conditions apart from eclampsia and epilepsy as cause for seizures. These 8 cases of non-eclamptic no epileptic seizure were due toneurocysticercosis (2), cerebral malformations (1fronto ethmoid encephalocele), brain tumours (2meningioma and glioma), cerebral infarcts (1-ischemic stroke), and 2 cases of posterior reversible encephalopathy syndrome (Table 2).

Table 2: Causes of seizure disorders $(n=97)$.

\begin{tabular}{|lll|}
\hline Causes & N & $\%$ \\
\hline Eclampsia & 66 & 68.04 \\
\hline Epilepsy & 23 & 23.71 \\
\hline Cerebral malformation & 1 & 1.03 \\
\hline Brain tumors & 2 & 2.06 \\
\hline Cerebral infarcts & 1 & 1.03 \\
\hline Neurocysticercosis & 2 & 2.06 \\
\hline $\begin{array}{l}\text { Posterior reversible encephalopathy } \\
\text { syndrome }\end{array}$ & 2 & 2.06 \\
\hline
\end{tabular}

Drugs used to control seizures were mainly magnesium sulphate, levitiracetam, phenytoin sodium, carbamazepine and lamotrigine. As maximum number of cases of seizures were due to eclampsia so magnesium sulphate was the most common drug used to control seizures (Table 3 ). In this study 36 patients had obstetrics complications. Premature rupture of membranes and gestational diabetes mellitus was found in 18 (18.54\%) women followed by hypothyroidism $(8.24 \%)$, anaemia (4.12\%), jaundice $(3.09 \%)$, abruption $(2.06 \%)$ and pulmonary tuberculosis in $1.03 \%$ patients (Table 4 ).

Table 3: Drugs used to control seizures.

\begin{tabular}{|lll|}
\hline Drugs & $\mathbf{N}$ & $\%$ \\
\hline Magnesium sulphate & 69 & 71.13 \\
\hline Levitriacetam & 11 & 11.34 \\
\hline Phenytoin sodium & 6 & 6.18 \\
\hline Carbamazepine & 4 & 4.12 \\
\hline Lamotrigine & 2 & 2.06 \\
\hline
\end{tabular}

Among mode of delivery $48(49.48 \%)$ patients had normal delivery, $10(10.30 \%)$ patients had preterm vaginal delivery and $2(2.06 \%)$ women had instrumental delivery by ventouse application. Cesarean section was done in 37 (38.14\%) women (Table 5). The live birth rate was $76.28 \%$ and still birth rate was $(23.71 \%)$. Among live birth 29 (29.89\%) neonates were healthy. Prematurity occurred in $27(27.83 \%)$, birth asphyxia in 6 $(6.18 \%)$, fetal growth restriction in $7(7.21 \%)$ and neonatal death was observed in $5(5.15 \%)$ cases (Table 6$)$. MRI proved a valuable diagnostic modality. It showed characterstic features of neurocysticercosis, meningioma, posterior reversible encephalopathy syndrome (PRES) and frontoethmoid encephalocele cerebral malformation and helped in making correct diagnosis (Figure 1-4). 
Table 4: Maternal complications $(n=36)$.

\begin{tabular}{|lll|}
\hline Complications & N & $\%$ \\
\hline Premature rupture of membrane & 9 & 9.27 \\
\hline Gestational diabetes mellitus & 9 & 9.27 \\
\hline Hypothyroidism & 8 & 8.24 \\
\hline Anaemia & 4 & 4.12 \\
\hline Jaundice & 3 & 3.09 \\
\hline Abruption & 2 & 2.06 \\
\hline Pulmonary tuberculosis & 1 & 1.03 \\
\hline
\end{tabular}

Table 5: Mode of delivery $(n=97)$.

\begin{tabular}{|lll|}
\hline Mode of delivery & N & $\%$ \\
\hline Normal delivery & 48 & 49.48 \\
\hline Caesarean delivery & 37 & 38.14 \\
\hline Preterm vaginal delivery & 10 & 10.30 \\
\hline Instrumental delivery & 2 & 2.06 \\
\hline
\end{tabular}

Table 6: Fetal and perinatal outcome $(n=97)$.

\begin{tabular}{|lll|}
\hline Outcome & N & $\%$ \\
\hline Still births & 23 & 23.71 \\
\hline Live births & 74 & 76.28 \\
\hline Healthy & 29 & 29.89 \\
\hline Premature & 27 & 27.83 \\
\hline Birth asphyxia & 6 & 6.18 \\
\hline Fetal growth restriction & 7 & 7.21 \\
\hline Neonatal deaths & 5 & 5.15 \\
\hline
\end{tabular}

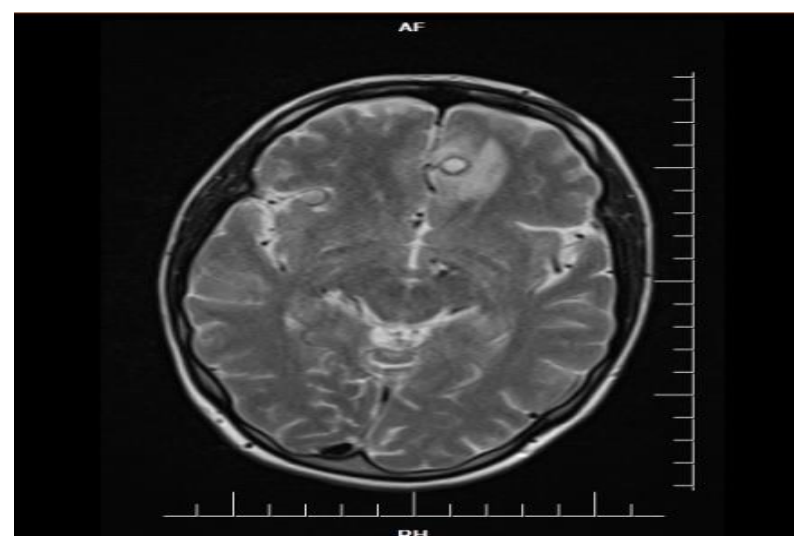

Figure 1: Magnetic resonance imaging shows multiple T2 hypointense nodular areas in bilateral frontal, occipital regions as calcified granulomas consistent with neurocysticercosis.

\section{DISCUSSION}

Seizures in pregnancy are associated with maternal and perinatal morbidity and mortality. Generalized tonicclonic seizures during pregnancy can lead to increased maternal trauma. If maternal trauma involves abdomen then there is risk of abruption which can lead to fetal hypoxia or death. Moreover, the risk of maternal aspiration can cause maternal hypoxia followed by fetal hypoxia.

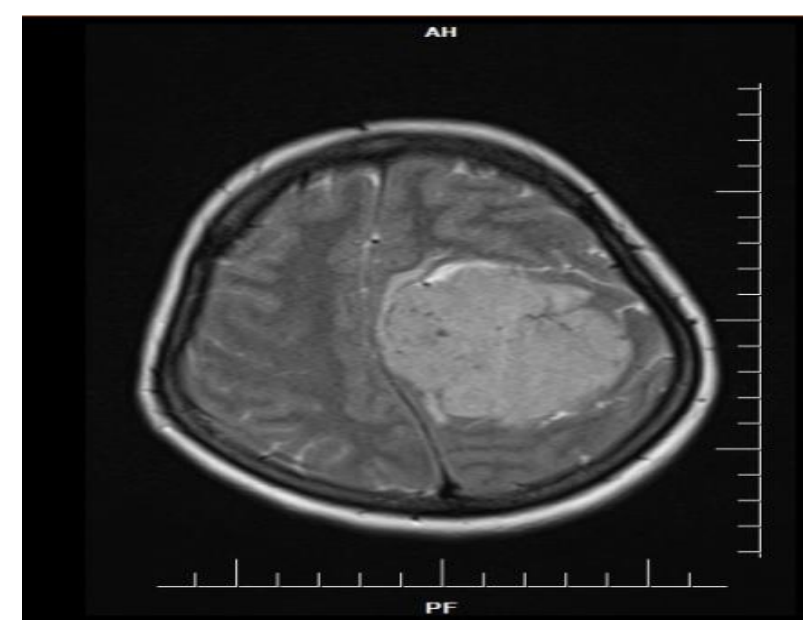

Figure 2: Magnetic resonance imaging shows T1 iso to hypointense lesion in left parietal region consistent with meningioma.

Eclampsia is a multisystem disorder of pregnancy and puerperium. It is associated with significant perinatal morbidity and mortality. Approximately $10-15 \%$ of maternal deaths are associated with eclampsia. ${ }^{5}$ The incidence of eclampsia in India is around $1.5 \%$.From 1980 to 2015 , the data analysis showed no reduction in its incidence. $^{6}$ In a study of 47 women with eclampsia by Brewer et al, seizures and headache were most common presenting symptoms in $87.2 \%$ women. $^{7}$ Seizures in eclampsia are usually of generalized tonic-clonic convulsion type and self limiting. Typically, eclamptic seizures do not last for more than 3 to 4 minutes. Most patients become responsive within 10 to 20 minutes. $^{8}$ Epilepsy is a common neurological disorder in obstetrics. Though majority of cases are uncomplicated but there are increased obstetric risks and increased adverse neonatal outcome, when compared to general population.

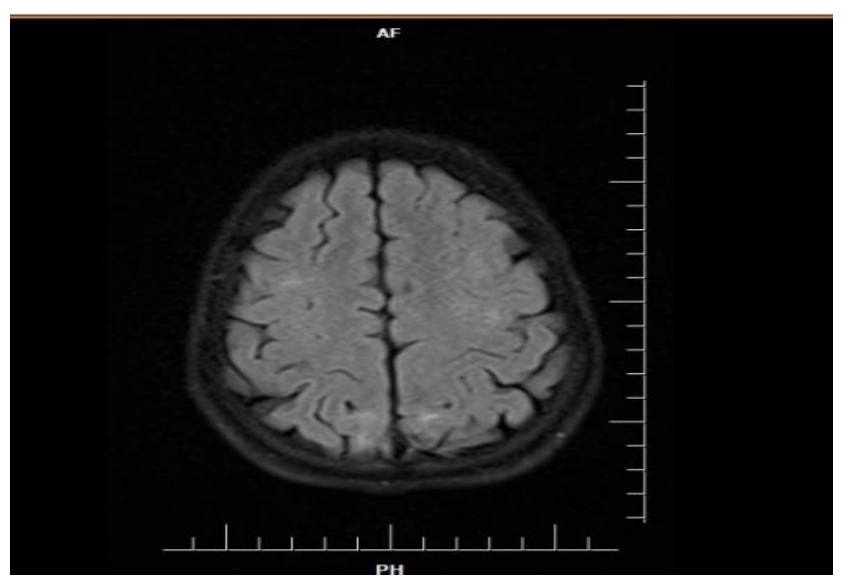

Figure 3: Magnetic resonance imaging shows Flair T2 W1 intensity in subcortical white matter in occipito parietal area consistent with posterior reversible encephalopathy syndrome. 
Frequency of seizures is increased during pregnancy in one third of women with epilepsy. ${ }^{9}$ Pregnant women with epilepsy have a 4 to $8 \%$ chances of giving birth to a child with malformations as compared to only 2 to $4 \%$ of general population. ${ }^{10}$ The type of anomalies are orofacial clefts, cardiac defects and neural tube defects but in present study no such anomalies were noted in infants born to pregnant women with epilepsy. In women on one antiepileptic drug congenital anomalies occur in 4 to 8 $\%$ and is probably greater in those receiving more than one antiepileptic drug. ${ }^{11}$ In present study we encountered many causes of seizures in pregnancy other than eclampsia and epilepsy like neurocysticercosis (NCC), brain tumor, cerebral infarct, posterior reversible encephalopathy syndrome, cerebral malformation which is similar to other studies. Various other studies and literature suggest that seizures in pregnancy can be beyond eclampsia and epilepsy. Hence the correct diagnosis, management plan and multimodality approach is essential for successful outcome.

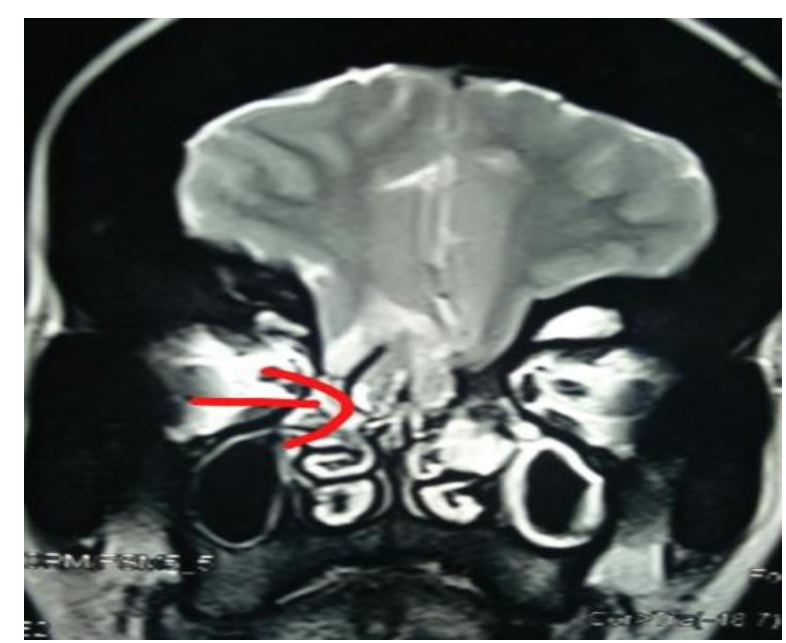

Figure 4: Magnetic resonance imaging shows herniation of bilateral basifrontal lobes and meninges along with bilateral olfactory nerves into bilateral ethmoid sinuses through bony defects in cribriform plates consistent with frontoethmoid encephalocele.

Neurocysticercosis is a rare, but an important cause of first-time convulsions in pregnancy. NCC is usually misdiagnosed as eclampsia and can be differentiated by imaging studies. Rebeca F et al reported maternal NCC presented with generalized seizures. Management is mainly directed at symptom control with antiepileptics. ${ }^{12,13}$ In this study two patients presented as brain tumor with pregnancy. One had meningioma and another had grade 3 glioma with history of seizures in pregnancy. Both underwent cesarean section under general anesthesia and delivered healthy babies. Meningioma in pregnancy is a rare occurrence but if present it is mostly symptomatic with complaints like headache, vomiting, visual disturbance, seizures or altered sensorium. Anoosha k Ravi et al reported two cases of meningioma in third trimester. Both of them underwent caesarean delivery under general anaesthesia. however neurosurgical excision of meningioma was done with delivery in second case. ${ }^{14}$ Pregnancy with headache and vomiting might be misdiagnosed as hyperemesis gravidarum, and seizure could present like that in eclampsia but presence of visual disturbances and neurological deficits should prompt the diagnosis of intracranial lesion. ${ }^{15} \mathrm{~A}$ retrospective study of 34 patients with glial brain tumors, suggested increased risk of tumor progression during pregnancy. ${ }^{16}$ The reported incidence of primary brain tumors in pregnant women is slightly lower, but relative frequencies of each brain tumor type appear to be similar for pregnant and nonpregnantwomen. ${ }^{17}$ Improvements in brain tumor treatments have led to an increase in the number of young women with brain tumors who are considering pregnancy. ${ }^{18}$ In present study two patients presented with posterior reversible encephalopathy syndrome (PRES). The neuroimaging showed cerebral edema affecting the parietal and occipital lobes of brain. PRES is a clinicoradiological entity characterized by acute headache, visual impairment, seizures and altered mental status. It has been associated with various systemic conditions such as hypertension, transplantation, renal failure and patients on high doses of chemotherapy. ${ }^{19}$ One case of pregnancy with generalized tonic-clonic seizures, altered sensorium was observed in this study. Her MRI brain showed ischemic brain infarcts suggestive of ischemic stroke. Stroke is an uncommon but serious potential complication of pregnancy and puerperium. However management remains a clinical challenge concerning the safety of both the mother and the unborn child. ${ }^{20}$ Pregnancy with cerebral malformation is a challenging situation associated with fetomaternal complications. In this study patient presented with term pregnancy having multiple seizures. She had history of trauma and cerebrospinal fluid rhinorrhea. Her MRI brain showed fronto-ethmoid encephalocele, deformed shape with tonsillar herniation through foramen magnum. Another study suggested that other cerebral malformations like arteriovenous malformations are associated with risk of cerebral hemorrhage and loss of capacity for decision making. ${ }^{21}$ In this study 36 patients had other obstetric complications like premature rupture of membranes, gestational diabetes mellitus (GDM), abruption etc. which is comparable to other study which also reported presence of hypertension, abruption, GDM along with seizures. ${ }^{22}$ In present study data of mode of delivery is different from another study who observed normal vaginal delivery in $62 \%$ of cases, LSCS in $27 \%$ cases and instrumental delivery in $10.8 \%$ cases. $^{22}$ Probably high number of cases of eclampsia were responsible for increase cesarean section rate and prematurity in present study. In this study in terms of fetal outcome the rate of still birth was higher $(23.71 \%)$ than other study $(8.57 \%){ }^{23}$

\section{CONCLUSION}

Seizure disorders in pregnancy are associated with increase in maternal and fetal risk. Current article 
emphasizes the fact that all convulsions in pregnancy are not due to eclampsia and epilepsy. When atypical features are present or clinical status worsens then a complete and continuous evaluation is crucial to differentiate eclampsia and epilepsy from other important differentials of seizures in pregnancy. A multidisciplinary approach with early diagnosis and management strategy is key to successful outcome.

\section{Funding: No funding sources}

Conflict of interest: None declared

Ethical approval: The study was approved by the Institutional Ethics Committee

\section{REFERENCES}

1. American academy of neurology. Practice parameter management issue for women with epilepsy report of the quality standards. Neurol. 1998;51:944-8.

2. Sibai BM, Stella CL. Diagnosis and management of a typical preeclampsia-eclampsia. Am J Obstet Gynecol. 2009;200:e1-7.

3. Thomas SV. Management of epilepsy and pregnancy. J Postgrad Med. 2006;52:57-64.

4. Mustafa A, İsmail Ö, Yavuz D, Süber D. Atypical preeclampsia andeclampsia: report of four cases and review of the literature. J Turkish-German Gynecol Assoc. 2010;11:115-7.

5. Saleem S, McClure EM, Goudar SS, Patel A, Esamai $\mathrm{F}$, Garces A, et al. A prospective study of maternal, fetal and neonatal deathsinlowandmiddleincome countries. Bull World Health Organ. 2014;92:605-12.

6. Nobis PN, Hajong A. Eclampsia in India through the decades. J Obstet Gynecol India. 2016;66:172-6.

7. Brewer J, Owens MY, Wallace K, Reeves AA, Morris $\mathrm{R}$, Khan M, et al. Posterior reversible encephalopathy syndrome in 46 of 47 patients with eclampsia. Am J Obstet Gynecol. 2013;208:468.e1-6

8. Wright WL. Neurologic complications in critically ill pregnantpatients. Handb Clin Neurol. 2017;141:65774.

9. Nathan J. Women with epilepsy. J Obstet Gynecol India. 2004;54:543-53.

10. More MJ. Epilepsy and pregnancy: minimizing the risks. Contemp Obstet Gynecol. 2004;49:51-70.

11. Meador KJ, Baker GA, Finnell RH. In utero antiepileptic drug exposure: fetal death and malformations. Neurol. 2006;67:407-12

12. Rebecca FD, Sher MN, Pooja D. Neurocysticercosis in pregnancy: maternal and fetal outcomes. Oxford Med Case Rep. 2016;7:138-40.
13. Garcia H, Nash T, Del Brutto O. Clinical symptoms, diagnosis, and treatment of neurocysticercosis. Lancet Neurol. 2014;3:1202-15.

14. Anoosha KR, Poonam S, Gauri G, Anubhuti R. Pregnancy with Meningioma: Report of Two Rare Cases. J Case Rep. 2017;7(3):322-4.

15. Kanaan I, Jallu A, Kanaan H. Management strategy for meningioma in pregnancy: A clinical study. Skull Base. 2003;13:197-203.

16. Yust-Katz S, John FG, Diane L, Jimin W, Ying Y, Mark DA. Pregnancy and glial brain tumors. NeuroOncol. 2014;16(9):1289-94.

17. Roelvink NC, Kamphorst W, van Alphen HA. Pregnancy-related primary brain and spinal tumors. Arch Neurol. 1987;44(2):209-15.

18. Claus EB, Black PM. Survival rates and patterns of care for patients diagnosed with supratentorial lowgrade gliomas: data from the SEER program,19732001. Cancer. 2006;106(6):1358-63.

19. Vandenbossche G, Maquet J, Vroonen P, Lambert G, Nisolle M, Kridelka F, et al. A reversible posterior leuco encephalopathy syndrome including blindness caused by preeclampsia. Facts Views Vis Ob Gyn. 2016;8:173-7.

20. Van Alebeek ME, de Heus R, Tuladhar AM, de Leeuw FE. Pregnancy and ischemic stroke: a practical guide to management. Curr Opin Neurol. 2018;31(1): 44-51.

21. Finnerty JJ, Chisholm CA, Chapple H, Login IS, Pinkerton JV. Cerebral arteriovenous malformation in pregnancy: presentation and neurologic, obstetric, and ethical significance. Am J Obstet Gynecol. 1999; 181(2):296-303.

22. Goel P, Devi L, Saha PK, Takkar N, Huria A, Dua D. Maternal and perinatal outcome in pregnancy with epilepsy. Internet J Gynecol Obstet. 2006;5:45-9.

23. Raji C, Sekar D. Prospective study of fetomaternal outcome in epilepsy in pregnancy in a tertiary care hospital. Int J Reprod Contracept Obstet Gynecol. 2017;6(11):5055-9.

Cite this article as: Sharma A, Gupta V, Sarda P, Singh P, Gupta N, Kohli S. Seizure disorders in pregnancy: an insight beyond eclampsia and epilepsy. Int J Reprod Contracept Obstet Gynecol 2021:10:4201-5. 